\title{
ACTFL Standards and Their Implications to Taiwanese English Teacher Education and Professional Development
}

\author{
Jia-Ying Lee ${ }^{1} \&$ Wen-Hau Fan ${ }^{2}$ \\ ${ }^{1}$ College of Education, The University of Iowa, Iowa City, USA \\ 2 Da-Gang Junior High School, Taoyuan, Taiwan \\ Correspondence: Jia-Ying Lee, College of Education, The University of Iowa, Iowa City, Iowa 52242, USA. \\ E-mail: jiaying0310@gmail.com
}

\author{
Received: February 3, $2012 \quad$ Accepted: April 25, $2012 \quad$ Published: June 1, 2012 \\ doi:10.5539/jel.v1n1p60 URL: http://dx.doi.org/10.5539/jel.v1n1p60
}

\begin{abstract}
In this globalized world, the growing importance of English learning has attracted more and more attention from researchers and educators, as the implementation of the new "English Lively Curriculum" in Taiwan demonstrates. The quality of English teachers is crucial in determining the quality of our English education, especially in an EFL environment like Taiwan. This study aims to examine the ACTFL Standards for the Preparation of Foreign Language Teachers in the US and their implications to English teacher education in Taiwan. Beginning with a review of foreign language teaching in the US, the ACTFL six new standards are introduced in detail. After this, the qualification processes and problems of the evaluation of English teacher education in Taiwan are discussed. Finally, by interviewing Taiwanese in-service English teachers, the possible implications of ACTFL standards to teacher education policy and institutions for Teacher Education in Taiwan are explored. Some of the implications include emphasizing the exposure to the ACTFL standards in Taiwanese teacher education programs and the need for a certificate from a well-organized English proficiency exam. In addition, the insufficient qualified English teacher and teaching resources in some rural districts should be improved by national policy.
\end{abstract}

Keywords: K-12 English teacher, ACTFL standards for the preparation of foreign language teachers, teacher education

\section{Introduction}

It is plain to see that the presence of English is world-wide. In Taiwan, for some people, learning English is for the purpose of preparing for high grades on the high school and college entrance exams; for others, it is a preparation for a competitive job market in the future. As Reagan \& Osborn (2001) observed, "in societies in which language learning is considered to be an essential component of a child's education, children routinely begin the study of foreign language very early in their schooling" (p. 3). This is clearly the case in Taiwan. Recently, with the implementation of "English Lively Courses" in Taipei County, English learning has become more and more prominent. Of the many factors determining the success of English education, the quality of teacher education is undoubtedly one of them (Chang, Fang, Chiu, Lee, 2007).

What makes a good teacher? The American Council on the Teaching of Foreign Languages (ACTFL, 1996) has program standards for the preparation of foreign language teachers, which were designed and approved by the National Council for Accreditation of Teacher Education (NCATE) in 2002 and updated in 2005. This is the first time that foreign language program standards were developed by the profession and accepted by NCATE. Beginning in 2004, foreign language teacher preparation programs in the United States undergoing NCATE review were required to base their program report submissions on the 2002 standards. As Chiang and Green (1995) observed, "a look at teacher education in Taiwan a decade ago was to look at teacher education in the US a half century ago" (p.52). However, very few, if any, studies have reported the ACTFL/NCATE and No Child Left Behind (NCLB, 2002) supplementary guidelines in the US as benchmarks. As a result, we hope the detailed exploration and the evaluation of foreign language teachers' requirements in the US will have significant implications for institutions focusing on K-12 English teacher education in Taiwan. 


\section{Foreign Language Teaching in the US}

Teaching is never easy. When the audience sees the conductor of an orchestra, it seems very easy for the conductor who only waves his arms and then the orchestra produces glorious sounds; this perception is especially to the novice. In the same way that conducting looks like hand-waving to the uninitiated, teaching looks simple from the perspective of others who only see a person talking and listening, handing out papers, and giving assignments (Darling-Hammomd \& Bransford, 2005). This idea is firstly defined by, Lortie (1975), who called it the apprenticeship of observation, the preconceptions new teachers bring to the task of becoming professionals based on when they were students observing their teachers. Students may perceive teaching to be easy because they only see the superficial trappings of teaching, but not the underlying knowledge, rationale and decision making processes. Thus, while we may not initially appreciate the effort of teaching, teaching is a very complex job.

Foreign language teaching in the US is becoming more complicated because of changes in the learning environment. In the past twenty years, the foreign language learning environment has moved from college preparation courses to required elements of elementary and secondary education. It is believed that language learning is designed to better prepare our youth for the knowledge and culture they must have in the multicultural society in US. As a result, many states are mandating foreign language curriculum for all students. With the students varying from the college-bound to younger learners, teachers are supposed to adjust themselves with different teaching approaches to include this new diversity (Tedick et al, 1993).

Since teaching is never an easy task, and learning to teach is a long-term process, it is important that future teachers get enough training to handle this new challenge before they start teaching. Freeman (1941) mentioned that teacher training is the most important factor in any educational field, since the formation of a teacher is the key to a successful educational program. Good teachers can transcend poor subjects or poor teaching programs while poor teachers could only impart very little to their students.

Before the mid 1970s, teachers were regarded as only "doers", that is to say, an implementer of subject content into the curriculum. Content was separated from teaching, so "how" to teach and "what" to teach were two totally different categories. In 1986, Shulman presented a widely held idea that teachers who are well-educated should have "pedagogical content knowledge", which is made up of both the component of content knowledge in the disciplines to be taught and the component of teaching knowledge. That is to say, learning to teach involves the mastering of specific content and mastering pedagogical knowledge (Huang, 2008). Shulman's idea may have significance value for foreign language teaching and learning worldwide. In that context, candidates from teacher preparation programs are either from foreign language departments or from colleges of education. Unfortunately, teachers in foreign language departments spend half of their time in their college studying literature without knowing how to teach it. At the same time, candidates from colleges of education may know the knowledge of teaching theory, but very often graduated with an insufficient ability to speak the foreign language well enough to teach it effectively (Glisan, 2002). So this remains a huge problem that needs to be solved.

\section{The ACTFL Six Standards}

In order to raise the teachers' quality, ACTFL Standards for the Preparation of Foreign Language Teachers were presented in 2002. The standards were based on the assumption that learning to teach is a complex, developmental process that starts with knowing the foreign language and its culture through the practices of teaching experiences in different social contexts.

The six standards for foreign language teachers go as follows.

Standard 1: Language, Linguistics, Comparisons

Standard 2: Cultures, Literatures, Cross-Disciplinary Concepts

Standard 3: Language Acquisition Theories and Instructional Practices

Standard 4: Integration of Standards into Curriculum and Instruction

Standard 5: Assessment of Languages and Cultures

Standard 6: Professionalism

Standards 1 and 2 emphasize the target language and culture that candidates should know. Standard 1 focuses on the sociolinguistic elements of a language that one needs to acquire in order to be able to communicate effectively. As Canale and Swain (1980) observed, communicative competence requires "knowing how, when, and why to say what to whom" (ACTFL, 1996); i.e., a performance-based language proficiency tailored to 
different situations and context, both in oral and written form. Because of this, spoken languages have been urged instead of the traditional grammar-translation ability. Standard 2 focuses on the sociocultural knowledge of understanding the relationships between practices, products, and perspectives of a target culture (ACTFL, 1996). This standard concentrates on both the relationships between cultural practices (behaviors accepted by a society), and products (piece of literature or rituals) with its perspectives.

Knowing the language and culture well does not ensure that a person becomes a competent language teacher. So the NACTE standards assume that content area must be combined with pedagogical knowledge. Standard 3 is based on second language acquisition research, which supports the provision of comprehensible input (Krashen, 1982) in the language classroom, given students the chance to express and negotiate meaning with others. The idea that people learn and develop through social interaction with others was proposed by Vygotsky (1978). This standard is also related to diverse populations with different learning styles proposed by Gardner (1995), in his discussion of the multiple intelligences.

Standard 4 is the integration of the five Cs mentioned in ACTFL: communication, cultures, connections, comparisons, and communities. Through the ACTFL standards, we see the emphasis on these concepts: connections to other subject areas using foreign languages; the importance of target cultures; and target language communities as a shared responsibility of learning among teachers, learners and parents.

As language learning and teaching experiencing changes, so too is language assessment. The assessment has shifted from traditional test format, such as the multiple-choice exam, to more authentic evaluations in which learners must demonstrate their practical command of skills (McNamara, 1996) and to exams that resemble real-life tasks. The movement of assessment has been geared to be more integrated with multiple modes of communication instead of relying on one-shot paper-pencil exams, which only test language ability partially.

Standard 6, the last one, underscores the five standards mentioned above. Without any one of them, it would be impossible.

\section{English Teacher Education in Taiwan}

In the Chinese society, education is highly valued and teachers have always been well-respected. In the past, teacher education used to be the responsibility of only those normal universities with a very prescriptive curriculum. With tuitions paid in full by the government, the teacher candidates would automatically get a teaching license when they graduate and would be assigned to their future working schools after one year of supervised internship. These students who received the government grants are then obliged to teach wherever they are needed for five years.

Teacher education in Taiwan has been under reform with the pass of "Teacher Professional Development Law" in 1994. After this reform, more and more universities are now allowed to have teacher education programs if they are approved by the government (Teacher Training Act, 1994). The learning content was changed as well. Instead of the existing Chinese literature courses, students in the English teacher education program are required to take credits in courses related to: language pedagogy, classroom management, theories in educational psychology or counseling, and educational leadership, totally up to 28 credits (Chiang and Green, 1995; MOE, 2007). In addition, the assumptions of teaching is to enhance students' integrated sills in listening, speaking, reading and writing as applicable productive skills to daily communication. Students who supported themselves can choose their internship places instead of being placed, and may go to either pubic or private schools. Or they may pursue other careers.

After the reform, more colleges and pre-services teachers will be involved in teacher preparation. Since there are more and more candidates, the process of becoming a teacher turned out to be more and more complicated. The situation intensified with the decline of birth rate each year, and teacher candidates now need to pass a test to get the license, and then be qualified for the assessment test for teachers in elementary/junior high schools. For instance, common experiences shows that passing the test to be a K-12 English teacher is getting more and more competitive, especially in those big cities with only around a 3\% acceptance rate according to the MOE (2008). It should be noticed that some problems reveled under such circumstances: who qualifies English teachers in Taiwan?

\section{Methodology}

The purpose of this research is to introduce the ACTFL standards for the foreign language teachers in the US, with the hope that these standards benefits both English teacher education programs and knowledge of English teachers in Taiwan. The focus is to understand the implications of ACTFL standards for Taiwanese English teachers' professional development and practices by interviewing 12 in-service teachers. Adopting qualitative 
research design, the interview addressed the research questions by exploring English teachers' understanding of the ACTFL standards as well as their comments related to Taiwanese teacher education programs and current teaching situations they observed.

\subsection{Research Questions}

1) Who constitutes and what qualifies the K-12 English teachers in Taiwan?

2) How well do the ACTFL standards being understood and being implemented to teaching by English teachers in Taiwan?

3) How could the current English teaching situations be changed by the implications of ACTFL standards?

\subsection{Participants}

In order to provide readers with unbiased and broader perspectives, four regions of Taiwan are divided as: the Taipei district, the Taichung district, the Tainan district, and the Tatung district. With three participants selected from each part, for the purpose of better representing English teachers in Taiwan, a total of 12 participants were recruited in this study. Among them, Seven participants were alumni from traditional normal universities, and five of them were from general universities who took additional teacher education credits. Those from traditional normal universities majored in education, while others majored in American and British literature or applied linguistics when in college. They are currently all English teachers in elementary or junior high schools in Taiwan, with at least three years of teaching experience in public or private schools.

\subsection{Interview}

The semi-structured interview was scheduled once with each participant in an empty classroom or in a conference room, and the interview were composed of three major questions. First, participants were required to give brief self introduction and to talk about their experiences in their journey to become an English teacher. Then, the six ACTFL standards were presented to each participant one by one, and participants were asked to express their familiarity of each standard or consult with the ACTFL definitions if not familiar with it. By this way, participants' understandings of the ACTFL standards were discussed and revealed. Finally, participants were required to comment on the teacher education programs they enrolled in before and to talk about current teaching situations with the strengths and weakness they observed. Participants were allowed to talk as long as they want, which lasted about two hours on average. All interviews were recorded and coded by the researcher, with all participants being anonymous and their interview information remains confidential. Another research assistant was hired to maintain the interreliability of the coding.

\section{Results and Analyses of Findings}

From the interview with our 12 participants, issues about the six ACTFL teacher education standards and the current situations of Taiwanese teacher education and in-classroom situations became clearer.

In terms of the Standards 1 and 2, all our participants admitted that they didn't have sufficient exposure to English sociolinguistic and sociocultural knowledge. The experiences of their own English learning journeys, either throughout their college experience or in the teacher preparation programs, had always been limited to the content of English grammatical knowledge. In one case, a participant specifically suggested that pragmatic feature, which includes the register of speech varieties and sociolinguistics aspects of language, or the cultural knowledge and its appreciation toward different cultural values, should be added to the English teacher preparation programs. As we know that learning a language is for the purpose of fluent communication, participants agreed that it is a big loss if our English teachers are limited to simple grammatical translation knowledge and to teaching students using a bilingual dictionary without many of the other important dimensions of language.

Regarding Standards 3 and 5, the situation was not so optimistic. With the pressure of getting students to score high in the entrance exams, our participants reported the limited flexibility they had in class regarding teaching content. Since what would appear in the entrance exam dominates the English curriculum, students are required to take as many mock exams as possible in order to prepare for their future entrance exam. Consequently, the traditional teacher-centered classroom with multiple-choice testing format still has the advantage because of easy classroom control and time efficiency. Thus, the multiple intelligences proposed by Gardner (1995) in Standard 3 remains difficult to put into practice due to the pursuit of high grades in the entrance exam, which focuses on reading and writing. The focus on exam preparation has other effects, and participants mentioned that although they were aware of the benefits and necessity of adopting authentic questions such as performance-based, portfolio assessment to cater to the diversity of students, there are still some difficulties for English teachers that 
want to use alternative forms of testing, as suggested in Standard

With regard to Standard 4, our participants mentioned that the responsibility of students' language learning should be shared by schools, parents and students themselves. However, one of our participants from Hualian mentioned that sometimes they face difficulties in equipping their students with multimedia English learning resources, not to mention taking on the sole responsibility for students' learning outcome. The situation is especially severe in the southern and eastern urban regions of Taiwan. Here, the participant pointed out the problem that while the major cities have many English "wandering teachers" who cannot get a permanent teaching position in a public school, some rural districts in Taiwan have always been struggling to recruit and retain their English teachers. Participants suggested that offering sufficient government incentives for teachers who are willing to move to high-need schools (Berry, Darling-Hammond, Hirsch, Robinson, Wise, 2006), as No Child Left Behind (NCLB, 2002) administered, might be a good way to increase the chances that those students in need have access to highly qualified teachers.

In addition, with each participant received a diploma from different major, they all urged that the teacher education programs should have a more balanced curriculum for pre-service teachers. For example, participants from the literature major reported feeling incompetent about the knowledge of pedagogy because there were only six credits required in the teacher education program. This emphasis accords with ACTFL statement, which suggests that the most effective foreign language curriculum is the one formed through a collaboration between foreign language departments, colleges of education, and practicing precollegiate foreign language teachers.

\section{Discussion and Implications}

According to the Year Book of Teacher Education Statistics issued in 2008 by the Taiwanese Ministry of Education, there are 12,238 elementary and secondary English teachers nationwide in Taiwan. The application of the standards in the US emphasizes teachers' performance and their professional judgment; however, this is not the case in Taiwan. Teachers and schools in Taiwan are evaluated only based on "how many of [their students] get into the top universities" or passed an important exam (Shive, 2000). Thus, the superficial trappings of lectures and assignments without the appreciation of knowledge are built into the whole system of evaluation. These measures serve to underscore only the most technical views of language learning, and they serve to encourage the most deskilled teaching approach (Meier, 2002). That's why Taiwanese TOEFL scores tend to again fall behind other Asian countries and why many Taiwanese students find themselves unable to communicate fluently when studying abroad.

All of our participants mentioned that Asian countries tend to be test-oriented, and so is the Taiwanese teacher qualification process. However, getting high scores on the one-shot English teacher qualification exam does not guarantee a highly-qualified English teacher. Candidates are only allowed for teaching demonstration if they pass the written exam, which could be less than $10 \%$ of the examinees. Again, the six Standards should be taken more seriously by both educators and pre-service teachers' preparation programs as criteria for our future English teachers.

Based on our aforementioned information from the interviews, we conclude that foreign language teachers must demonstrate their proficiency in the language and the culture they are going to teach. For example, it is believed that the TOEFL or ACTFL OPI interview is recognized to be able to truly reflect those candidates' achievement in the language to be taught, and will ultimately improve the quality of teacher education programs (Schrier, 2001). With the notion that only the adequately qualified can teach in the classroom, it might be a necessary requirement that teacher candidates must demonstrate proficiency in speaking and writing at the "Advanced Low" level described in the ACTFL Proficiency Guidelines, as implemented in the US (Glisan, 2002). As a result, the implementation of the authentic tests implied by Standard 5 could solve the problem as it addressed the prior lack of systematical evaluation that checks if teachers actually have the ability to teach. Through the performance-based test we mentioned above, certification as a highly qualified teacher could more truly reflect a teacher candidate's skills.

Some argue that the tenure assurance of professional placement is detrimental to both teachers' motivation to strive toward excellence and their students. In order to make our English teachers into life-long learners themselves, English education in Taiwan can adopt No Child Left Behind (NCLB, 2002) which hopes to close the students' achievement gap by closing the teaching quality gap (Berry, Darling-Hammond, Hirsh, Robinson, Wise, 2006). As a result, in order to solve the limitations to the Taiwanese teacher qualification tests which inevitably lead to the insufficiencies of English teachers, all of our participants agreed that Taiwanese educational institutions should ensure that foreign language candidates, even the substitute teachers, possess sufficient knowledge in the ACTFL six standards areas: language, linguistics, comparison; cultures, literatures, 
cross-disciplinary concepts; language acquisition theories and instructional practices; integration of Standards into curriculum and instruction; assessment of languages and cultures; and finally professionalism.

While there is much to be done, these standards provided by the US give new impetus for foreign language professionals concerning teacher qualification and ways teacher education programs can best prepare for them. For example, the foreign language standards provided a schema to help people understand what dimensions of teaching are important. And a powerful way to build schema is to develop a sense from guided observations and engagement in practice, so that candidates might better know what teaching is. Therefore, we hope that someday a creative coherent system of teacher development will provide students with caring, competent and qualified teachers.

\section{References}

ACTFL. (1996). Standards for foreign language learning: Preparing for the 21th century. New York, NY: American Council on the Teaching of Foreign Language.

ACTFL/NCATE Standards Document. (2005). Retrieved from http://www.actfl.org/files/public/ACTFLNCATEStandardsRevised713.pdf

Berry, B., Darling-Hammond, L., Hirsch, E., Robinson, S., \& Wise, A. (2006). No child left behind anthe 'highly qualified' teacher: The promise and the possibilities. Center For Teaching Quality. Retrieved from http://www.cep-dc.org/nclb/hqt/oct2006/Center\%20for\%20Teaching\%20Quality_NCATE_Robinson\%20(O ct\%20Joint\%20Submission).pdf

Canale, M., \& Swain, M. (1980). Theoretical bases of communicative approaches to second language teaching and testing. Applied Linguistics, 1, 1-47. http://dx.doi.org/10.1093/applin/1.1.1

Chang, S. J., Fang, D. L., Chiu, A. L., \& Lee, C. H. (2007). The Evaluation of Institutions for Teacher Education: The Evaluation System of NCATE and Its Implications. Kaohsiung Normal University Journal, 22, 1-20.

Chiang, L. H., \& Green, J. E. (1995). A Comparison of Teacher Education Reform in Two Nations: The Republic of China and the USA. Action in Teacher Education, 17(2), 47-54. http://dx.doi.org/10.1080/01626620.1995.10463243

Darling-Hammond, L. (2005). Educating the new educator: Teacher education and the future of democracy. The New Educator, 1, 1-18. http://dx.doi.org/10.1080/15476880490441379

Darling-Hammond, L., \& Bransford J. (2005). Preparing Teachers for a Changing World: What teachers should learn and be able to do. Hoboken, NJ: John Wiley \& Sons.

Freeman, S. A. (1941). What Constitutes a Well-Trained Modern Language Teacher? Modern Language Journal, 25, 293-305. http://dx.doi.org/10.1111/j.1540-4781.1941.tb03010.x

Glisan, E. W. (2002). New directions: K-12 foreign language teacher preparation. In A.R. Poliakoff (Ed.), Foreign languages: Early language learning, standards for teacher preparation, national security. Basic Education, 46(8), 8-12.

Huang, Y. C. (2008). Teacher's Professional Development in a Study Group. Journal of Educational Development and Research, 4(1), 83-108.

Krashen, S. (1982). Principles and Practice in Second Language Acquisition. NY: Pergamon.

Lortie, D. (1975). Schoolteacher: A Sociology Study. London: University of Chicago Press.

McNamara, T. (1996). Measuring Second Language Performance. Harlow, Essex, UK: Addison Wesley Longman Ltd.

Meier, D. (2002). Will standards save public education? Boston, MA: Beacon.

Reagan, T., \& Osborn, T. (2001). The Foreign Language Educator in Society: Toward a critical pedagogy. New Jersey, NJ: Lawrence Erlbaum Associates, Inc.

Schrier, L. L. (1989). A survey of Foreign Language Teacher Preparation Patterns and Procedures in Small, Private Colleges and Universities in the United States. Unpublished Dissertation, Ohio State University.

Schrier, L. L. (2001). Developing precollegiate foreign language teachers: An overlooked mission of foreign language departments. In E. B. Wells \& D. Goldberg (Eds.), Chairing the Foreign Language and Literature Department, Part 2 ( 2nd ed., pp. 71-78). New York: Modern Language Association

Shulman, L. S. (1986). Those who understand: Knowledge growth in teaching. Educational Researcher, 15(2), 
$4-14$.

Shive, G. (2000). Confucian Legacy and Examination Reform in Taiwan. Retrieved from http://newviews.freehosting.net/ testing.html

Teacher Training Act of 1994. (1994). Office of the President, Republic of China, Taipei, Taiwan.

Tedic, D. J., et al. (1993). Second Language Education in Tomorrow's Schools. Guntermann, p. 43-75.

Vygotsky, L. S. (1978). Mind and society: The development of higher psychological processes. Cambridge, MA: Harvard University Press. 